\title{
DIE ABFASSUNG DES FÉLIRE VON OENGUS.
}

In der Neuausgabe des Heiligenkalenders ${ }^{1}$ ) hat Stokes seine frühere Meinung aufgegeben, die Angaben der Vorreden wiesen ihn einer viel $\mathrm{zu}$ frühen Zeit $\mathrm{zu}$; er schliefst sich jetzt vielmehr mit Recht den Beweisgründen Strachans an, dals die Sprache $\mathrm{zu}$ einem rund um 800 entstandenen Denkmal sehr wohl passe. In den Angaben über Verfasser und Abfassung des Werkes p. XXVI gibt er möglichst genau die Notizen der irischen Vorreden wieder, ohne zu untersuchen, wie weit sie glaubwürdig sind; und doch ist ja nicht zweifelhaft, dafs diese erst einer späteren Zeit entstammen.

Oengus hat aber zum Glück selber genügende Angaben gemacht, nach denen die Abfassungszeit annähernd genau bestimmt werden kann. Einen Terminus post quem gibt zunächst der Tod seines Lehrers (aite) Mael-Ruain, des Gründers von Tallaght, im J. 792,2) den er sowohl im Prolog 225, als im Innern des Kalenders am 7. Juli und wieder im Epilog $64 \mathrm{f}$. als gestorben erwähnt. Schon darum ist die Angabe der Vorrede (p. 6) unglaubwürdig, Oengus habe den Anfang in Cuil Bennchuir gedichtet, das Hauptstück in Cluain Eidnech und nur das Ende in Tamlacht; denn es ist nicht anzunehmen, dafs er erst nach dem Tod seines verehrten aite in dessen Gemeinschaft eingetreten ist. Die Vorreden lassen ihn zur Zeit des Oberkönigs Aed Oirdnide dichten, der 797-819 regiert hat; sie geben auch den Grund an, weshalb sie das tun: ar is é ro gab rige nÉirenn $i$ ndiaid Donnchada, uair ticc Oengus isin broluch thóisech ind

1) Félire Oengusso Céli Dé. The Martyrology of Oengus the Culdee, Henry Bradshaw Society. London 1905.

2) Ann. Ult. s. a. 791. Stokes gibt p. XXVI das unrichtige Datum 787, dagegen p. 432 das richtige. 
félire tar bás Donnchada (p. $2=8$ ) 'denn er (Aed) ist König von Irland geworden nach Donnchad, da Oengus im Prolog des Felire Donnchad als gestorben erwähnt.' Das bezieht sich auf Vers 221 des Prologs. Yachdem Oengus die vergangenen GröIsen dieser Welt den Frommen und Heiligen gegenübergestellt und ausgeführt hat, wie jene spurlos dahin sind, ihre Burgen in Trümmern liegen, ihre Gräber zum Teil unbekannt sind, während die Stiftungen der Heiligen blühen und ihre Gräber Wunder tun und viele Leute anziehen, wendet er sich zur Neuzeit mit Vers $217 \mathrm{ff}$. :

Tathunn ni as nesa arar súil - salm sobail! de neurt Dé - dian medair! - indiu deud domain. Donnchad dric rúad rogdae nó Bran búadach Berbae, ni beir dinn snim lobrae athigid a mmemrae. Mael-Ruain iarna goiri, grían már desmaig Mide, occa lecht co nglaini icthair cnet cech cridi.

'Wir haben etwas Näheres vor Augen von Gottes Kraft, heute am Ende der Welt. Donnchad, der grimmige, starke, auserwählte, oder Bran von der Barrow, der siegreiche, - der Besuch ihrer Schreine nimmt uns den Kummer der Schwäche nicht weg. Mael-Ruain nach seiner Frömmigkeit, die grolse Sonne auf der Südebene von Mide, - bei seinem reinen Grab wird das Seufzen jedes Herzens geheilt.'

Es wird also dem kürzlich verstorbenen Frommen, MaelRuain, der ebenfalls tote irische König Donnchad (769-797) gegenüber gestellt, und mit Recht schliefst der Verfasser der Vorrede daraus, dals das Gedicht unter seinem unmittelbaren Nachfolger Aed verfalst sei. Denn zur Zeit späterer Könige hätte es keinen Sinn gehabt, gerade ihn hier zu nennen; es wird gewissermalsen auf sein frisches Grab hingewiesen. Der Vers ist also nach 797 gedichtet. Ebenso mufs es sich mit 'Bran von der Barrow' verhalten. Wie schon der Glossator des Lebor Brecc gesehen hat, ist der König von Leinster, Bran Ardchenn mac Muiredaig, gemeint, der 795 durch seinen Nachfolger Finśnechta ums Leben gebracht wurde;1) Bran Berba heifst er

1) Ann. Ult. s. a. 794; Book of Leinster 39 b. Stokes, der ihn gegen den Glossator in der ersten Ausgabe CCXXVI mit dem viel früheren Leinsterkönig Bran-Dul identifiziert hatte, nennt ihn in der neuen p. 404 'a heathen king'. 
poetisch, weil die Barrow der Hauptflufs von Leinster ist. Eben unter diesem Nachfolger, Finsinechta Cetharderc mac Cellaig, hat also Oengus gedichtet. Die Annalen melden von ihm, dals er sich 804 dem Oberkönig Aed unterwerfen mulste. Doch scheint er keine Treue gehalten zu haben; denn schon 805 veranstaltete Aed einen Kriegszug nach Dun-Cuair an der Grenze von Mide und Leinster') und teilte Leinster unter zwei andere Prinzen des einheimischen Königshauses, die beide Muiredach hiefsen, während Finșnechta ins Kloster mufste. Aber es gelang ihm diese zu besiegen und 806 das Königtum wieder zu gewinnen, bis er 808 in Kildare an Hämorrboiden starb. Man darf vielleicht vermuten, dafs die Dichtung vor die Zeit seiner Absetzung (805) fällt; aber jedenfalls sind die äufsersten Zahlen 797 und 808, wie ich schon KZ. 37, 54 bemerkt habe. Und mit solch annähernder Datierung dürfen wir schon zufrieden sein.

Es erklärt sich nun auch ohne weiteres, wie die Legende entstanden ist, Fothad na Canoine und Oengus hätten sich gegenseitig ihre Gedichte gezeigt und gesegnet. ${ }^{2}$ ) Denn unter demselben Jahre, wo die Unterwerfung von Bran unter Aed berichtet wird, ${ }^{3}$ ) erzählen die Annalen: Isin bliadain si dana ro saeradh (1. saertha) cleirich Herend ar fecht 7 ar sluaiged la hAed Oirnigi do bhreith $\dot{F}$ athaidh na Canoine 'in demselben Jahr wurden die Kleriker Irlands von Kampf und Kriegszug befreit durch Aed Oirdnide nach der Entscheidung von Fothad na Canoine'. Die Vorrede gebraucht fast dieselben Worte, nur dals sie die beiden Jahre 804 und 805 durcheinander wirft:4) Ocus is forin sluagad sin (nämlich nach Dun-Cuair, a. 805) ro saertha clerig Erenn ar fecht 7 sluagad; ar is e Fothad na Canoine ruc in breith, dia ro saertha eculsa Erenn. Die Quelle der Legende ist also nicht zweifelhaft; derselbe Glossator, der den Bran des Gedichts an der Hand von Annalen identifizierte, mag der Erfinder dieser Begegnung zwischen Oengus und Fothad sein.

1) Nach O'Donovan wohl Rathcore in der Grafschaft Meath.

8) Vorrede p. $4=10$.

3) Ann. Ult. 803 (= 804).

4) Die Vier Meister a. 779 haben ihr das nachgemacht.

Freiburg i. B.

R. Thurneysen. 